\title{
UMA PROPOSTA DE REESTRUTURAÇÃO DOS CANAIS DE DISTRIBUIÇÃO COMO VANTAGEM COMPETITIVA NO VAREJO DE ALIMENTOS
}

\author{
A PROPOSAL OF RESTRUCTURING OF THE WAYS OF \\ DISTRIBUTION LIKE COMPETITIVE \\ ADVANTAGE IN RETAIL FOODS
}

Recebido em 25.03.10 / Aceito em 22.09.10

\begin{abstract}
Marcos Livato ${ }^{1}$ e Gideon Carvalho de Benedicto ${ }^{2}$
\end{abstract}
\section{Resumo}

Os novos "moldes" de competitividade têm sugerido que as atenções sejam voltadas para uma eficiente gestão da cadeia de suprimentos no setor supermercadistas, do produtor ao consumidor final dos produtos, reduzindo seus custos operacionais. Sabe-se que a eliminação de algumas dessas fases de intermediação dentro dos canais de distribuição pode representar, para os pequenos e médios varejistas, uma importante vantagem competitiva, com a eliminação dos custos adicionais cobrados pelos intermediários. O objetivo deste trabalho é propor um modelo de reestruturação dos canais de distribuição no varejo brasileiro de alimentos por meio da estratégia cooperativa, induzindo à eliminação dos intermediários. A pesquisa bibliográfica serviu de base para a definição da metodologia desta pesquisa, que foi realizada por meio de um estudo observacional junto a dezenove Centrais de Negócios Supermercadistas no Estado de São Paulo. Para a coleta dos dados, foi elaborado um questionário com perguntas fechadas. Após a coleta dos dados e tabulação, foram aplicadas técnicas quantitativas de análise de dados por meio do sistema SAS. O estudo pretende discutir a proposta das redes de cooperação como alternativa estratégica, com a possibilidade de eliminação de algumas fases de intermediação dentro dos canais de distribuição. Varejo.

Palavras-chave: Estratégia. Redes de cooperação. Cadeia de suprimentos. Canais de distribuição.

\footnotetext{
1 Mestre em Administração de Empresas pela UNISAL. Professor da disciplina de Custos e Tarifas Logísticas do curso de Logística e Transportes do Centro Paula Souza - FATEC Americana e professor de Contabilidade do curso de Administração de Empresas da Faculdade Network. Consultor de Varejo. E-mail: livato@uol.com.br

2 Doutor em Ciências Contábeis pela FEA/USP. Professor e pesquisador da Universidade Federal de Lavras (UFLA). Email: gideon.benedicto@gmai.com
} 


\begin{abstract}
The new "molds" of competitiveness have suggested that the attentions should be focused on an efficient management of the supply chain in the supermarket departments, starting from the producer until the end user of the products, reducing the operational costs. It's known that the elimination of some of these stages of intermediation of the ways of distribution can represent to the small and mediums retailers an important competitive advantage, with the elimination of the additional costs charged by the intermediaries. The objective of this work is to propose a model of restructuring of the ways of distribution in the brazilian retail of food through of the strategy, inducing the elimination of the intermediaries. The search of the bibliography was used like basement to the definition of the methodology of this search, that was realized through of an observational study realized with nineteen Central Business Supermarket $s$ in the state of São Paulo. To do the collection of the datas was prepared a questionary with specific questions. After the collection of the datas and tab, were used techniques quantitive of analysis of datas through of SAS system. The study intends to discuss the proposal of the cooperation's networks like a strategic alternative, with the possibility of elimination of some phases of intermediation of the distribuition's ways.
\end{abstract}

Keywords: Strategic. Cooperation networks. Supply chain. Distribuition's ways. Retail.

\title{
INTRODUÇÃO
}

A abertura da economia na década de noventa, no Brasil, possibilitou a concorrência ao setor supermercadista. A entrada de novos players no mercado impulsionaram as empresas nacionais a desenvolverem estratégias e novos modelos de gestão, visando a garantir a sua sustentabilidade. A mudança contínua de hábito dos consumidores, mais informados e exigentes, e o avanço da tecnologia também contribuem para a concorrência no varejo nacional.

Esses fatores têm provocado uma reestruturação no setor, obrigando as empresas nacionais a desenvolverem novos modelos organizacionais, mais dinâmicos e flexíveis, e que possam atender às exigências impostas pelo ambiente em que estão inseridas essas organizações.

Atualmente, o desenvolvimento de estratégias que possam garantir a sustentabilidade das empresas no curto e longo prazo são tarefas impostas aos gestores da administração do varejo. As influências exercidas pelos ambientes interno e externo às organizações requerem uma avaliação constante das ações planejadas e implementadas para que os objetivos possam ser alcançados.

No setor supermercadista, pequenas e médias empresas estão utilizando de estratégias de cooperação, por meio da formação de Centrais de Negócios, como forma de garantir a sua sustentabilidade no mercado competitivo. O conceito de associativismo, na forma de redes de cooperação interempresariais, tem sido desenvolvido gradativamente em diversos setores do varejo brasileiro, podendo ser encontrado, atualmente, em lojas dos ramos de materiais de construção, farmácias e supermercados, entre outros setores que se organizam em rede.

Para Olivares (2002, p.13), "[...] o contexto das organizações nos últimos anos vem sofrendo uma série de mudanças estratégicas, estruturais e operacionais, que estão provocando grande impacto na gestão moderna".

O conceito de redes de empresas vem ganhando destaque como alternativa estratégica desenvolvida pelas empresas de diversos setores da economia mundial, buscando obter algum tipo de vantagem competitiva. Gulati (1998) define redes de empresas como grupos de pessoas ou organizações ligadas por um conjunto de relações sociais com um fim específico.

Segundo Amato Neto (2005, p. 17-18), "as redes estratégicas interorganizacionais constituem-se, portanto, em uma alternativa quanto à forma de organizar a produção de bens e/ou serviços e podem ser utilizadas pelas empresas na busca de melhoria de sua posição competitiva". Diante dessas exigências, a literatura tem-se apresentado com tendência crescente e intensa à proposta de uma estrutura organizacional em rede.

Embora a utilização do termo rede, na forma de se descrever as organizações contemporâneas, seja recente, para Cabral (1999, p.132), "a noção de redes como um modo de se pensar sobre as organizações não é nenhuma novidade, tendo estado presente nas ciências sociais, 
mais precisamente na antropologia, sociologia e psicologia, desde a década de 50", e Amato Neto (2005, p. 18) afirma que "a concepção de cooperação via rede de empresas não é algo verdadeiramente novo no cenário das organizações e que várias formas de alianças estratégicas entre empresas e organizações na forma de joint-ventures, consórcios, já se constituem em práticas empresariais há algum tempo".

Entre as diferentes formas de se obter alguma fonte de vantagem competitiva sugere-se que as atenções sejam voltadas para uma eficiente gestão da cadeia de suprimentos no setor supermercadistas, desde o produtor até o consumidor final dos produtos, reduzindo seus custos operacionais. Sabe-se que a eliminação de algumas dessas fases de intermediação dentro dos canais de distribuição pode representar, para os varejistas, uma importante vantagem competitiva, com a eliminação dos custos adicionais cobrados pelos intermediários.

O objetivo deste trabalho é propor um modelo de reestruturação dos canais de distribuição no varejo brasileiro de alimentos por meio da estratégia cooperativa, induzindo à eliminação dos intermediários.

\section{RELAÇÕES INTERORGANIZACIONAIS}

As definições encontradas na literatura consideram a formação de redes como característica própria de mercados competitivos, em que empresas assumem o estabelecimento de parcerias buscando atingir aos seus objetivos.

Para Cabral (1999, p. 144), "embora as empresas continuem sendo teoricamente descritas como unidades autônomas, com limites bem definidos, na prática elas se inserem em uma densa rede de inter-relacionamentos e arranjos, ao mesmo tempo competitivos e cooperativos".

Em um estudo recente sobre os enfoques dos trabalhos científicos na área de estratégia envolvendo cooperação, publicada pelo Strategic Management Journal, Begnis, Pedrozo e Estivalete (2005) destacam os estudos sobre o processo de formação das configurações interorganizacionais de base cooperativa.

No quadro 1, apresenta-se um resumo dos estudos publicados sobre a construção dos arranjos cooperativos.

\begin{tabular}{|c|c|}
\hline \multicolumn{2}{|r|}{ Strategic Management Journal } \\
\hline \multicolumn{2}{|r|}{ Formação dos Relacionamentos } \\
\hline Autores & Enfoques Teóricos \\
\hline Doz (1996) & $\begin{array}{l}\text { Explora a evolução da cooperação por meio de alianças estratégicas entre firmas, } \\
\text { utilizando o enfoque da Teoria Organizacional e abordando a questão do Aprendizado } \\
\text { Organizacional, tendo por objetivo avaliar a contribuição relativa das condições iniciais e } \\
\text { do processo evolucionário do aprendizado nos resultados de alianças estratégicas. }\end{array}$ \\
\hline $\begin{array}{l}\text { Dollinger, Golden e Saxton } \\
\text { (1997) }\end{array}$ & $\begin{array}{l}\text { Enfatizam o papel da reputação dos parceiros sobre a decisão de se implementar uma } \\
\text { estratégia de cooperação. A confiança derivada da reputação dos parceiros, não só se } \\
\text { apresenta como fator de sucesso das estratégias cooperativas, mas também é elemento } \\
\text { chave do processo de sua formação. }\end{array}$ \\
\hline Sakakibara (1997) & $\begin{array}{l}\text { Apresenta a proposição de que a heterogeneidade das capacitações dos participantes de } \\
\text { consórcios de P\&D representa uma condição para distinguir dois motivos para a } \\
\text { cooperação: o compartilhamento de custos e o compartilhamento de habilidades. }\end{array}$ \\
\hline Gulati (1999) & $\begin{array}{l}\text { Desenvolve um estudo dinâmico do papel dos recursos da rede na determinação da } \\
\text { formação d as alianças. Os resultados desse estudo confirmam as observações de que } \\
\text { recursos que são acumulados pelas redes surgem da própria participação das firmas nas } \\
\text { redes e das suas experiências acumuladas em alianças antecedentes. }\end{array}$ \\
\hline Tsai (2000) & $\begin{array}{l}\text { Trata da dinâmica evolucionária da formação de redes por meio da análise de como as } \\
\text { unidades organizacionais criam novas ligações interunidades para a troca de recursos. }\end{array}$ \\
\hline Chung, Singh e Lee (2000) & $\begin{array}{l}\text { Afirmam que a base sobre a qual se formam as alianças entre as organizações depende da } \\
\text { complementaridade dos recursos, da similaridade do status das organizações envolvidas e } \\
\text { do capital social. Acrescentam que o capital social surge das experiências colaborativas } \\
\text { diretas e indiretas das organizações e o capital social assume um importante papel na } \\
\text { formação de alianças. }\end{array}$ \\
\hline $\begin{array}{l}\text { Kale, Singh e Perlmutter } \\
(2000)\end{array}$ & $\begin{array}{l}\text { Consideram que uma das maiores razões para que as firmas participem de alianças é } \\
\text { adquirir know-how e capacidades dos seus parceiros de aliança, mas, ao mesmo tempo, as } \\
\text { firmas buscam se proteger do comportamento oportunista de seus parceiros, retendo seus } \\
\text { próprios ativos essenciais. }\end{array}$ \\
\hline
\end{tabular}

Quadro 1 - Resumo das publicações sobre a construção de arranjos cooperativos Fonte: Elaborado pelos autores a partir de Begnis, Pedrozo e Estivalete (2005, p.8-9). 
Para Begnis, Pedrozo e Estivalete (2005), as publicações sobre estratégias de cooperação, encontradas no Strategic Management Journal, nos primeiros anos da década de 1990, são marcadas pela apresentação do tema cooperação como nova forma de arranjo interorganizacional voltado à melhoria do desempenho das empresas.

A complexidade dos negócios e o acirramento da concorrência requerem das empresas ações imediatas que auxiliem nas soluções dos problemas e que, muitas vezes, atuando isoladas, seriam incapazes de resolver.

Segundo Casarotto e Pires (2001, p. 49): "Existe em curso uma forte tendência ao desenvolvimento de mecanismos organizativos inter-empresariais que são frequentemente utilizados para a reestruturação do aparato produtivo do território e para a modernização das empresas", melhorando seu desempenho e tornando-as mais competitivas no mercado.

As relações interorganizacionais são motivadas pela aquisição de competências necessárias para a sobrevivência das empresas e que podem ser encontradas por meio das redes de cooperação.

Oliver (1990 apud KWASNICKA, 2006, p. 36) descreve "a existência de seis aspectos críticos que motivam os relacionamentos entre empresas: necessidade, assimetria, reciprocidade, eficiência, estabilidade e legitimidade":

- Necessidade: uma organização frequentemente estabelece ligações e trocas com outras organizações por necessidade para alcançar artefato legal. A dependência de recursos e a facilidade de trocas acentuam as interações voluntárias e a cooperação entre as organizações;

- Assimetria: o relacionamento é sugerido pelo potencial exercício do poder ou con trole sobre outra organização ou sobre seus recursos. Tanto o desejo pelo controle como a relutância para desistir dele refletem o motivo assimétrico nas decisões organizacionais para a interação;

- Reciprocidade: as parcerias acontecem devido ao potencial de reciprocidade, isto é, da mutualidade dos benefícios conseguidos pela sua formação, sendo esta funda mentada na cooperação, colaboração e coordenação entre as organizações, em vez de dominação, poder e controle;

- Eficiência: a busca pela eficiência pode motivar as empresas a formarem parcerias. Nessa situação, a formação de um relacionamento interorganizacional é sugerida pela tentativa de uma empresa reduzir seus gastos internos e melhorar sua rentabilidade;

- Estabilidade: devido ao dinamismo do ambiente empresarial, as organizações são estimuladas a estabelecer relacionamentos, a fim de obterem certa estabilidade, inovação e segurança nas suas relações com os outros, antecipando, prevendo e absorvendo incertezas;

- Legitimidade: o estabelecimento de relacionamentos interorganizacionais, com o propósito de aumentar a legitimidade, pode ser originado da intenção das organizações de melhorar sua reputação, imagem e prestígio.

As razões da existência de estruturas organizacionais em rede podem variar de acordo com as contingências, sendo modificadas, adaptadas e aprimoradas por meio do poder de negociação dos seus integrantes. Para Amato Neto (2005, p. 17), "as redes estratégicas interorganizacionais constituem-se em uma alternativa quanto à forma de organizar a produção de bens e/ou serviços e podem ser utilizadas pelas empresas na busca de melhoria de sua posição competitiva". Na figura 1, apresenta-se o modelo de uma rede de empresas supermercadistas, concorrentes entre si, denominadas neste trabalho como Centrais de Negócios, e os principais agentes envolvidos nos relacionamentos. 


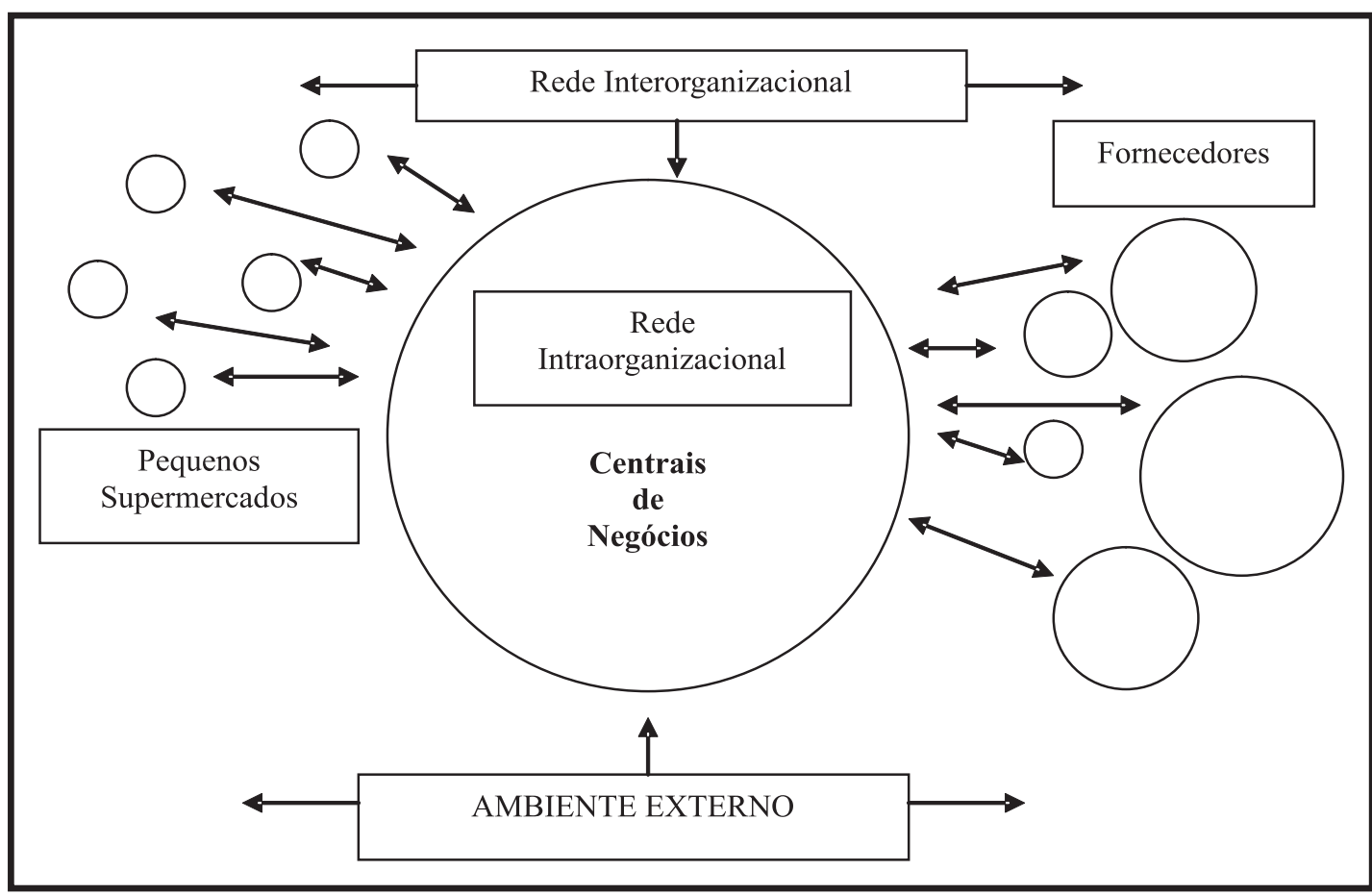

Figura 1 - Redes de empresas supermercadistas Fonte: Elaborado pelos autores.

Na rede intraorganizacional, representada pelas Centrais de Negócios, são tratados os assuntos estratégicos, os relacionamentos internos entre os parceiros envolvidos, solução de possíveis conflitos e a execução dos processos operacionais, levando ao cumprimento das ações decorrentes da decisão estratégica dos seus participantes.

No ambiente da rede interorganizacional estão envolvidos todos os agentes externos, que podem influenciar ou não as empresas da rede, destacando-se o governo, o mercado financeiro, agências reguladoras, fornecedores, clientes e os concorrentes.

A pequena empresa supermercadista, envolvida nesse arranjo organizacional, encontra acesso à informação e novas tecnologias, além de estruturas mais dinâmicas e flexíveis. As ações conjuntas representam ganhos de escala e proporcionam melhores margens. A soma das forças resultantes das parcerias é sempre maior que as conquistadas individualmente, sem que os participantes percam suas identidades e características individuais.

\section{CANAIS DE DISTRIBUIÇÃO}

Para disponibilizar as mercadorias aos consumidores finais, os produtores utilizam os canais de distribuição. Segundo Kotler (2000, p. 510), "a maioria dos fabricantes não vende seus produtos diretamente para os consumidores finais, utilizando-se de intermediários que constituem um canal de marketing, também chamado canal comercial ou canal de distribuição".

Na figura 2, apresentam-se os diversos tipos de canais de distribuição que uma mercadoria pode percorrer até chegar à sua aquisição pelo consumidor final. 


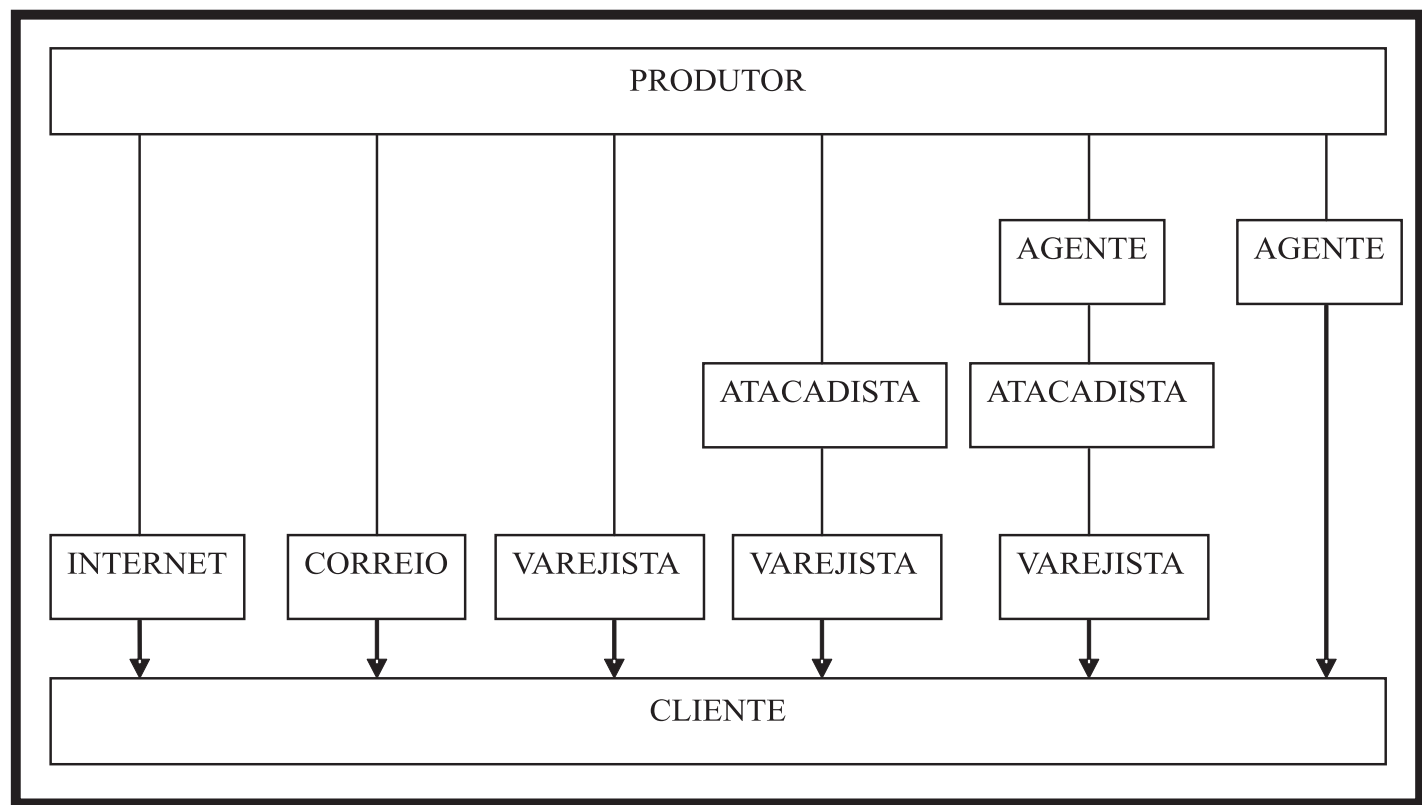

Figura 2 - Tipos de canais de distribuição

Fonte: McDonald (2004, p. 350).

A gestão eficiente dos canais de distribuição pode proporcionar ganhos para toda a cadeia de suprimentos, desde o produtor até o consumidor final dos produtos, reduzindo seus custos operacionais.

Corroborando com essa ideia, Ferrell e Hartline (2005, p.17) afirmam que "a meta da gestão de distribuição e cadeia de suprimentos é essencialmente levar o produto para o lugar certo, na hora certa, nas quantidades certas, ao menor custo possível". Para os autores, as empresas que se dão ao trabalho de construir sistemas de distribuição altamente eficientes podem baixar seus custos operacionais e criar uma vantagem competitiva sobre as empresas rivais.

Por outro lado, sistemas de distribuição ineficazes colocam em risco toda a cadeia de suprimentos (BALLOU, 1998; NOVAES, 2004). Geralmente, uma gestão eficiente da cadeia de suprimentos passa despercebida pelos consumidores, enquanto as interrupções ocasionam a falta de um produto na prateleira e podem ser notadas facilmente.

Para disponibilizar seus produtos aos consumidores finais, os produtores utilizam-se dos intermediários dentro dos canais de distribuição. Para McDonald (2004, p. 355), "o papel de um intermediário é prover os meios para conseguir a mais ampla cobertura de mercado possível a um custo unitário mais baixo".

Ferrell e Hartline (2005, p. 250-251) afirmam que "as principais funções dos intermediários no canal de distribuição são":

- Seleção: os fabricantes fazem apenas um produto enquanto os consumidores precisam de uma ampla variedade e um sortimento profundo de diferentes produtos. Ao selecionarem produtos no canal, os intermediários superam essa discrepância de sortimento;

- Fragmentação: os fabricantes produzem grandes quantidades de um produto para obter os benefícios de economias de escala. Mas os consumidores querem apenas uma unidade de determinado item. Ao fragmentar os produtos no canal, os intermediários, especialmente os varejistas, superam essa discrepância de quantidade; 
- Manutenção de estoques: uma vez que os fabricantes não podem fazer produtos sob encomenda, o canal deve fornecer a armazenagem dos produtos para futura compra e uso. Ao manter estoque, os intermediários superam essa discrepância temporal;

- Manutenção de locais convenientes: uma vez que fabricantes e consumidores estão separados geograficamente, o canal deve superar essa discrepância espacial disponibilizando os produtos em locais convenientes;

- $\quad$ Provisão de serviços: os canais agregam valor aos produtos ao oferecer serviços facilitadores (seguro, armazenagem, financiamento) e padronizar o processo de troca (processamento de pagamentos, entrega, precificação).

A utilização dos canais intermediários pode representar custos adicionais para serem incorporados aos preços dos produtos. Na medida em que os produtos percorrem diversos canais intermediários para serem disponibilizados aos consumidores finais, seus custos tendem a aumentar. Na visão de McDonald (2004, p.350), "em alguns negócios os custos de distribuição podem alcançar $20 \%$ do preço de venda" de um produto.

Na medida do possível, a eliminação de algumas dessas fases de intermediação dentro dos canais de distribuição pode representar, para os varejistas, uma importante vantagem competitiva, com a eliminação dos custos adicionais cobrados pelos intermediários.

Para as pequenas empresas varejistas, a eliminação de algumas dessas fases é mais difícil. A negociação direta com os produtores esbarra em barreiras relacionadas à logística. O volume reduzido de compras e a necessidade de entregas fracionadas, porta a porta, muitas vezes inviabilizam a negociação.

Outro fator é a imposição de alguns produtores em negociar apenas sua linha completa de itens, os chamados mix de produtos, utilizando seu poder de barganha na negociação. Como as pequenas empresas varejistas negociam pequenas quantidades de produtos e necessitam dessas entregas fracionadas, acabam sendo obrigadas a recorrer aos intermediários, atacadistas e distribuidores, pagando preços mais altos e impactando suas reduzidas margens operacionais.

O desenvolvimento de redes de cooperação apresenta-se como uma alternativa estratégica para os pequenos varejistas conseguirem obter o acesso às negociações diretas com as indústrias, por meio do aumento do volume de compras dos produtos negociados em conjunto com os integrantes da rede.

Segundo um estudo recente, encomendado pela Associação Brasileira de Distribuidores (ABAD) à LatinPanel, no espaço de apenas um ano (1 ${ }^{\circ}$ sem/2006 a $1{ }^{\circ}$ sem/2007), caiu de $23 \%$ para $8 \%$ o número de varejistas que comprava quase todo o seu estoque com o atacado distribuidor (MADUREIRA, 2007).

Essa reestruturação no canal de distribuição poderá despertar o interesse das indústrias em desenvolver negociações com esses novos clientes. Segundo Wilder (2003, p. 117), "[...] as grandes indústrias, por exemplo, durante a década de 80 , focavam sua venda direta às grandes redes de supermercados, deixando os pequenos varejistas ao encargo dos distribuidores e atacadistas".

Porém, com o aumento do poder de negociação das grandes redes, essas indústrias mudaram de estratégia e começaram a atender as redes médias e também pequenas com as quais têm maior poder de barganha, reduzindo a importância dos atacadistas. Na pesquisa de campo realizada por Pigatto e Alcântara (2006, p. 6), analisando as relações entre pequenas e médias empresas supermercadistas e fornecedores, destacam que, atualmente, "[...] algumas redes varejistas começaram a atrair atenção das empresas fornecedoras; em alguns casos, redes que até então eram atendidas por meio de atacadistas, passaram a receber a visita de vendedo- 
res ou representantes do fornecedor". Para esses autores, essa alteração de comportamento, em que as indústrias estão reconhecendo os pequenos e médios varejistas como parceiros importantes e as redes varejistas adotando uma postura mais impositiva, é resultado das alterações econômicas, sociais e tecnológicas observadas no mercado e, ainda, exemplo de como o poder pode mudar de mãos e continuar sendo operado da mesma maneira.

$\mathrm{O}$ acesso às compras diretamente das indústrias por meio dessas redes permite a eliminação de alguns intermediários e poderá garantir aos pequenos varejistas, além das vantagens de redução dos preços dos produtos adquiridos, o desenvolvimento de ações conjuntas de marketing, tais como: campanhas promocionais, divulgação por meio de tabloides. Além das ações anteriormente citadas, também se pode aumentar o conjunto de serviços oferecidos, por exemplo, por meio de repositores nas áreas de venda das lojas.

\section{PROCEDIMENTOS METODOLÓGICOS}

A pesquisa bibliográfica serviu de base para a definição da metodologia deste estudo. Realizou-se um estudo observacional junto a dezenove Centrais de Negócios Supermercadistas no Estado de São Paulo, associadas à Associação Paulista de Supermercados (APAS). Segundo Oliveira (1997, p.122), "entende-se por pesquisa bibliográfica o ato de fichar, relacionar, referenciar, ler, arquivar, fazer resumos de assuntos relacionados com o campo da pesquisa em questão".

Para a coleta dos dados, foi elaborado um questionário com perguntas fechadas, que foi aplicado no $1^{0}$ semestre de 2007. Após a coleta dos dados e sua tabulação no software Excel, foram aplicadas técnicas quantitativas de análise de dados por meio do sistema SAS (WLAKER, 1997).

A comparação de médias de medidas observadas antes e depois da associação foi feita por meio da aplicação de testes para dados pareados, considerada a ferramenta estatística mais apropriada para essa situação.

A seleção do teste mais apropriado foi feita por meio de um estudo de suposições que avaliou a normalidade aplicando o teste de Shapiro-Wilk (1965) e que, se verificada, conduziria à aplicação do teste t de Student para dados pareados. Na ausência de normalidade, foi avaliada a simetria, a qual, se verificada, conduziria a maior adequação do teste de Wilcoxon das ordens assinaladas. Por fim, não sendo detectadas simetria nem normalidade, o recomendado é a aplicação do teste do Sinal.

\section{APRESENTAÇÃO E ANÁLISES DOS RESULTADOS}

Foram estudados os percentuais de compras realizados pelos associados nos diferentes canais de distribuição, atacado, distribuidor e indústria, antes e após a associação.

O teste para dados pareados se baseia na diferença das quantidades compradas de cada um dos canais de distribuição, antes e após a associação na rede. Sendo assim, três variáveis foram definidas para análise: 


\section{1)Diferença Atacado (DA)}

$\mathrm{DA}=\mathrm{CAD}-\mathrm{CAA}$

Onde:

$\mathrm{CAD}=$ Quantidade de compras no atacado depois da associação $\mathrm{CAA}=$ Quantidade de compras no atacado antes da associação
2) Diferença Indústria (DI)
$\mathrm{DI}=\mathrm{CID}-\mathrm{CIA}$
Onde:
$\mathrm{CID}=$ Quantidade de compras na indústria depois da associação
$\mathrm{CIA}=$ Quantidade de compras na indústria antes da associação

\section{3) Diferença Distribuidor (DD)}

$\mathrm{DD}=\mathrm{CDD}-\mathrm{CDA}$

Onde:

$\mathrm{CDD}=$ Quantidade de compras no distribuidor depois da associação

$\mathrm{CDA}=$ Quantidade de compras no distribuidor antes da associação

Cada uma dessas variáveis sofreu uma análise independente, a qual permitiu testar a hipótese de nulidade de que a diferença é igual a zero. A igualdade a zero corresponde à inexistência de mudanças nas quantidades de antes e depois. Foi assumido em todas as situações um nível de significância de 5\% (á=0,05). Inicia-se a apresentação dos resultados pelo teste de Shapiro-Wilk, apresentado na tabela 1.

Tabela 1 - Estatística W do teste de Shapiro-Wilk e valor-p

Tabela 1 - Estatística W do teste de Shapiro-Wilk e valor-p

\begin{tabular}{lll}
\hline Canal Distribuição & W & valor-p \\
\hline Atacado & 0.95985 & 0.56934 \\
Indústria & 0.92710 & 0.15315 \\
Distribuidor & 0.90713 & 0.06558 \\
\hline
\end{tabular}

A partir dos resultados obtidos utilizando-se do teste de Shapiro-Wilk (1965), verificamse indícios (valor-p $<0,10$ ) de que a diferença entre os valores observados antes e depois do segmento Distribuidor não provêm de população normalmente distribuída. Em relação às diferenças observadas nas demais condições estudadas (Atacado e Indústria), não há indícios de que os dados não sejam normais.

Não havendo indícios de não aderência à distribuição normal, segue-se para a análise do teste t de Student apresentado na tabela 2.

Tabela 2 - Resultado dos testes t de Student para dados pareados e do teste de Wilcoxon das ordens assinaladas para cada um dos segmentos estudados

\begin{tabular}{lrrrr}
\hline Segmento & $\mathbf{t}$ & valor-p & S & valor-p \\
\hline Atacado & -9.2552 & $<.00001$ & -95.0 & $<.0001$ \\
Indústria & 10.4298 & $<.00001$ & 95.0 & $<.0001$ \\
Distribuidor & -2.0966 & 0.05042 & -18.5 & 0.0625 \\
\hline
\end{tabular}


Nos segmentos Atacado e Indústria, há fortes indícios $(p<0,01)$ da existência de diferenças entre as quantidades compradas antes e após o estabelecimento da associação. A complementação do estudo pode ser feita por meio da observação das médias e limites de confiança das diferenças, conforme apresentado na tabela 3.

Tabela 3 - Média, desvio padrão e limites do intervalo de confiança

\begin{tabular}{lrcrr}
\hline & & \multicolumn{2}{c}{ Limites do Intervalo } \\
& & & \multicolumn{2}{c}{ de Confiança (95\%). } \\
Canal de Distribuição & Média & Desvio padrão & Superior & Inferior \\
Atacado & -29.6842 & 13.9803 & -22.9459 & -36.4225 \\
Indústria & 34.7895 & 14.5395 & 41.7973 & 27.7816 \\
Distribuidor & -5.1053 & 10.6139 & 0.0104 & -10.2210 \\
\hline
\end{tabular}

Observa-se que a média da diferença no canal de distribuição Atacado é negativa, indicando que os valores observados antes são maiores que os valores observados depois. Isto significa a existência de uma redução no volume de compras feitas neste segmento.

A média observada no canal de distribuição Indústria, por sua vez, é positiva, indicando um aumento do volume de compras neste segmento. Em ambos os casos, os limites de confiança não se aproximam do zero, indicando que esta diferença é significativa e não casual.

Já no caso do segmento Distribuidor, a média é negativa, indicando uma redução no volume de compras neste segmento, entretanto, os limites de confiança atravessam o zero, e daí a inexistência de indícios de diferença significativa pelos testes estatísticos previamente aplicados. No entanto, esta transposição para os valores positivos é muito pequena, podendo indicar que, muito possivelmente, até exista uma redução nos volumes também neste segmento.

Outra forma de se avaliar estas diferenças é na simples observação dos volumes antes e após a associação, conforme apresentado no gráfico 1. Nota-se que a participação da Indústria nos processos de negociação de compra era pequena, sendo que $79 \%$ das compras realizadas pelas empresas, antes da associação, ocorriam nos canais de Atacado e Distribuidores.

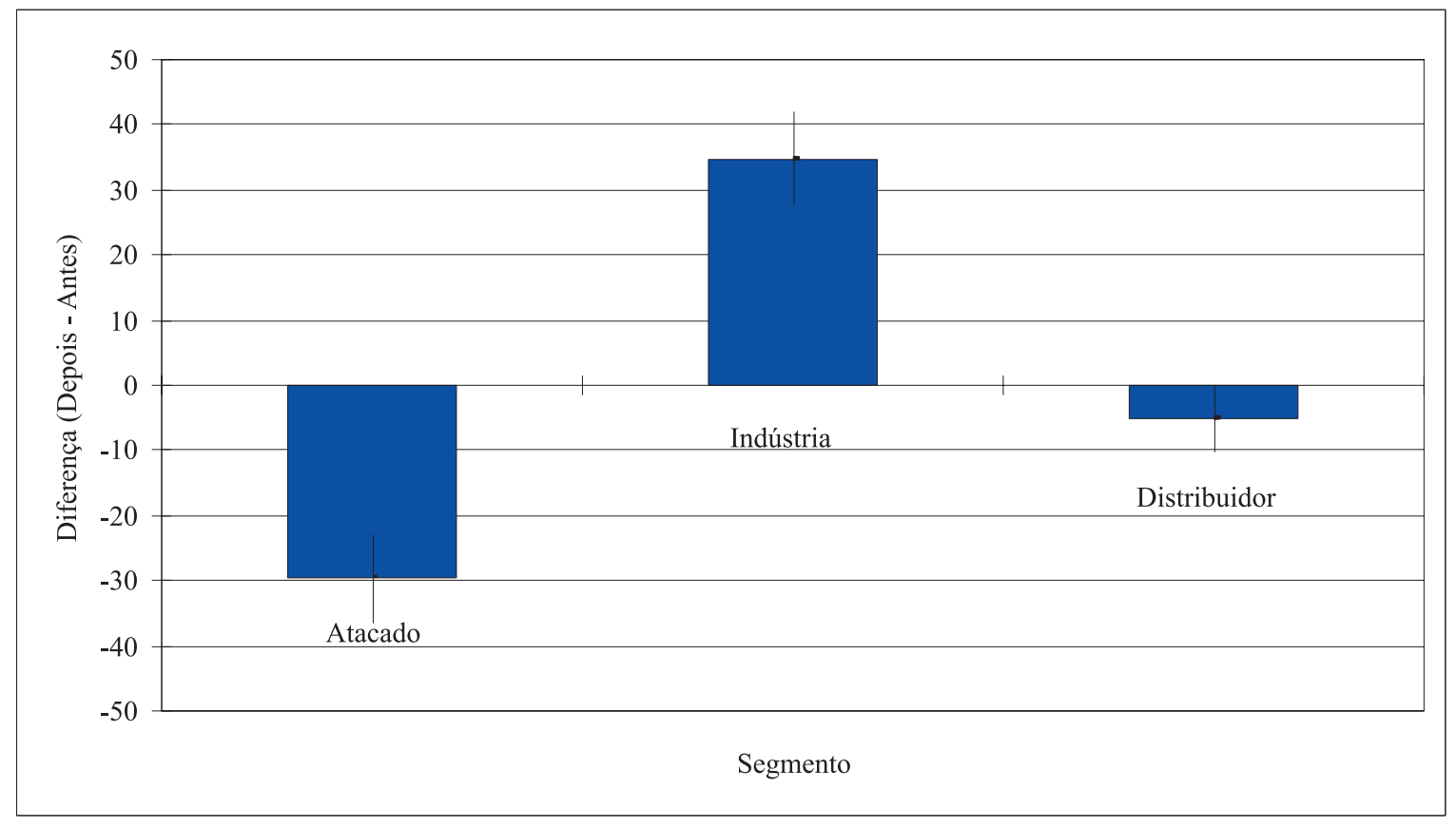

Gráfico 1 - Comparação entre médias das diferenças observadas nos diferentes segmentos estudados à luz dos limites dos intervalos de confiança (95\%) 
Esse fator impactava nos preços das mercadorias vendidas pelos pequenos supermercadistas. O Atacadista e o Distribuidor atuam como um intermediário entre a Indústria e essas empresas, aplicando suas margens de lucro sobre os preços dos produtos e repassando para seus clientes, tornando-os mais caros, se comparados aos praticados pelas Indústrias. Segundo McDonald (2004, p.350), "em alguns negócios os custos de distribuição podem alcançar $20 \%$ do preço de venda" de um produto.

Além dos preços menores, outro aspecto importante que tem influenciado a negociação entre as partes está relacionado ao volume de serviços reduzidos oferecidos pelos atacadistas em relação aos das indústrias.

Adotando a estratégia do associativismo, os pequenos supermercadistas conseguiram ter acesso às compras diretamente da Indústria, com a possibilidade de redução de preços dos produtos negociados, o aumento do mix de produtos, a oferta de serviços agregados pelos fornecedores e as negociações de ações de marketing conjuntas, reduzindo os custos dos associados. No gráfico 2, apresenta-se o comparativo das médias de compras nos canais de distribuição atacado, distribuidor e indústria, antes e após a associação.

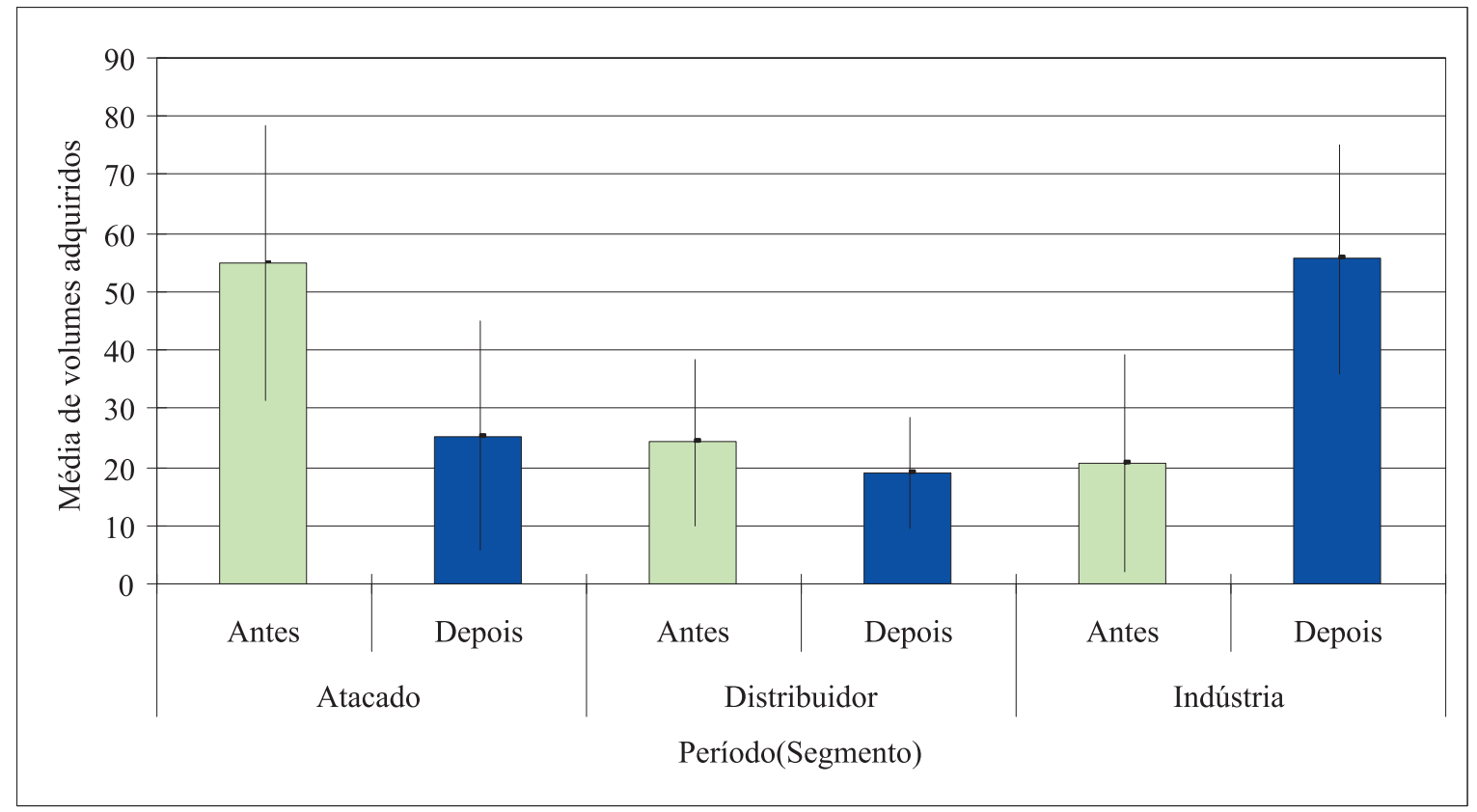

Gráfico 2 - Médias de compras nos diferentes canais de distribuição antes e após a associação

No gráfico 2, observa-se um crescimento na participação do canal de distribuição Indústria, depois da associação, elevando de 20,79 para 55,58\%. Em contrapartida, a participação do canal de distribuição Atacado sofreu uma queda de 55 para 25,32\%. Assim, verifica-se um deslocamento na participação entre canais na ordem de $25 \%$ do Atacado para Indústria. Para Wilder (2003, p. 122), “a busca na redução dos custos levou as redes a centralizarem suas compras e, quando possível, o recebimento e a distribuição dos produtos, passando a atuar no lugar dos atacadistas".

A estratégia de associação nas Centrais de Negócios propiciou, aos pequenos supermercadistas, o aumento do volume de compras negociado com os fornecedores, promovendo o acesso às compras direto da Indústria. 
Essa migração dos canais de distribuição Atacado e Distribuidor para a Indústria poderão acarretar uma reestruturação dos canais de distribuição do varejo de alimentos em virtude da perda de uma parcela significativa de clientes pelos atacadistas e distribuidores.

Uma proposta de reestruturação dos canais de distribuição no varejo brasileiro de alimentos é apresentada na figura 3.

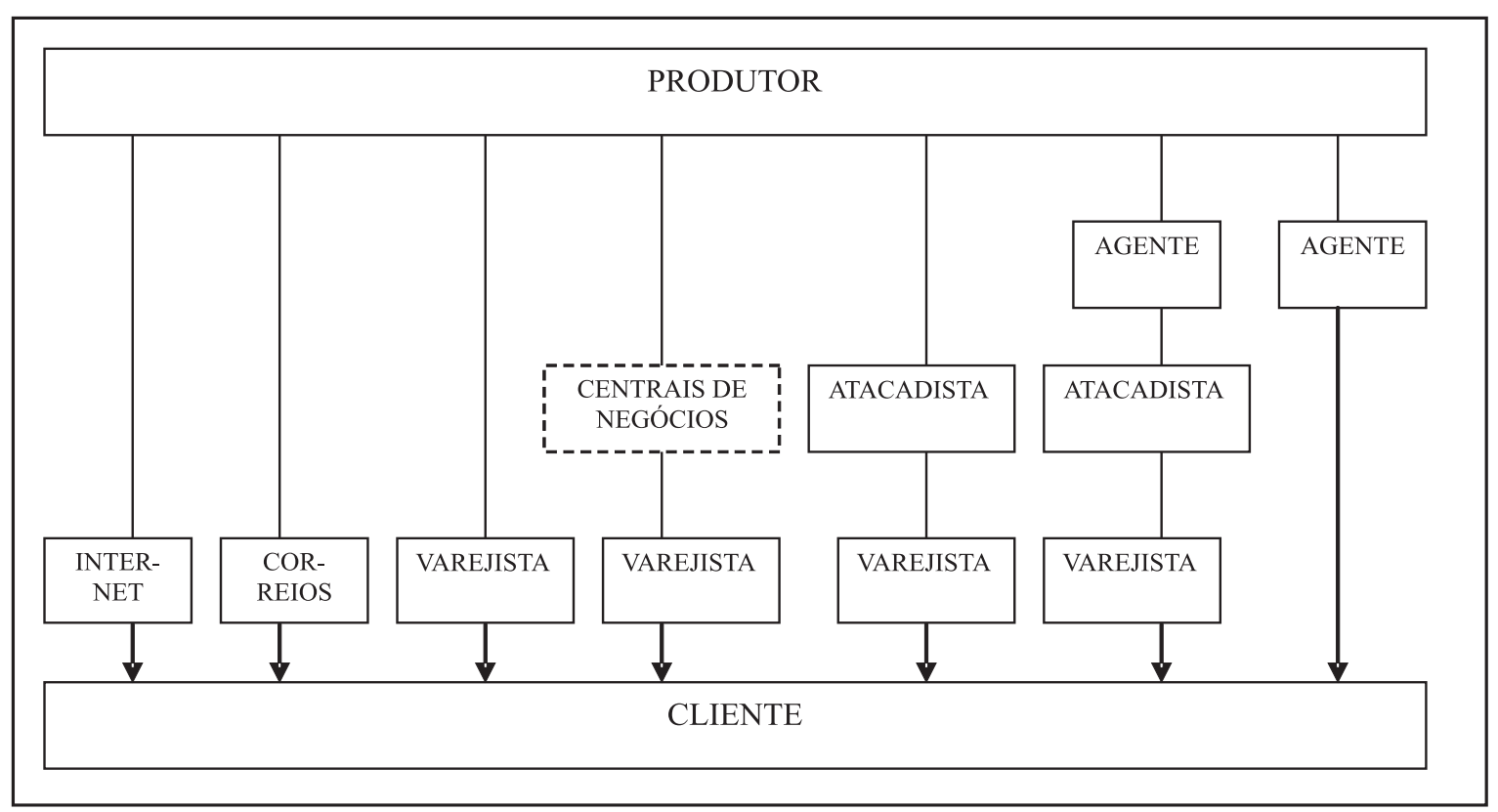

Figura 3 - Proposta de reestruturação dos canais de distribuição Fonte: Elaborado pelos autores.

A formação de Centrais de Negócios entre pequenos e médios supermercadistas poderá propiciar, para essas empresas, condições favoráveis de negociações junto às grandes indústrias do setor.

O desenvolvimento de relações do tipo ganha-ganha representará vantagens competitivas para as partes, uma vez que, para o pequeno e médio supermercadista, o acesso às compras direto das indústrias representará reduções de custos e a oportunidade de oferecer as marcas líderes em seu mix de produtos, atraindo clientes para as lojas e, consequentemente, a possibilidade de aumentar o seu faturamento.

Para as indústrias, o crescimento das Centrais de Negócios representará uma oportunidade de desenvolver um novo canal de distribuição, atendendo regiões onde as grandes redes não atuam e as negociações eram dificultadas em razão dos volumes reduzidos negociados pelos pequenos varejistas atuando de forma isolada.

\section{CONSIDERAÇÕES FINAIS}

Dos resultados apresentados, utilizando-se de técnicas estatísticas, pode-se concluir que, com a eliminação de algumas fases de intermediação dentro dos canais de distribuição, consideráveis reduções dos custos adicionais cobrados pelos intermediários podem ser atingidas e isso pode ser considerado como uma importante vantagem competitiva por parte dos varejistas. As variações entre as quantidades compradas antes e após o estabelecimento da associação entre 
supermercadistas permitem observar um crescimento na participação do canal de distribuição Indústria, depois da associação, em torno de $25 \%$. Em contrapartida, a participação do canal de distribuição Atacado sofreu uma queda na mesma ordem de grandeza.

A estratégia de associação nas Centrais de Negócios propiciou aos pequenos supermercadistas o aumento do volume de compras negociado com os fornecedores, promovendo o acesso às compras direto da Indústria. As negociações em conjunto podem propiciar redução de preços dos produtos negociados, o aumento do mix de produtos nas lojas, a oferta de serviços agregados pelos fornecedores e as negociações de ações de marketing conjuntas, reduzindo os custos operacionais dos associados e beneficiando a cadeia de suprimentos do setor.

Para as indústrias, o desenvolvimento das Centrais de Negócios poderá representar uma nova oportunidade de distribuição para que seus produtos cheguem até os consumidores finais. Essa reestruturação dentro dos canais de distribuição permitirá para as indústrias, além da oportunidade de desenvolvimento de novos clientes, amenizarem os impactos provocados pelo poder de negociação das grandes redes supermercadistas instaladas no país.

O avanço das negociações entre as partes, baseado em operações ganha-ganha, representará uma importante vantagem competitiva dentro do canal de distribuição, representando redução de custos de transação nas operações e permitindo que novos consumidores tenham acesso à um mix maior de produtos ofertados pelas indústrias.

Mesmo que os resultados dessa pesquisa apresentem algumas limitações, sobretudo por se restringirem ao contexto das redes de cooperação supermercadistas desenvolvidas no estado de São Paulo, suas evidências empíricas sugerem que a atuação em redes propicia às pequenas e médias empresas o acesso às compras direto das indústrias, aumentando seu poder de negociação em razão do volume negociado, atraindo a atenção das indústrias para o desenvolvimento de negociações. Para uma maior comprovação dos resultados apresentados e para o crescimento dos estudos empíricos sobre estratégias de cooperação, os autores sugerem a realização da pesquisa em outras regiões do país como em outros setores que desenvolvam relacionamentos em redes de cooperação.

\section{REFERÊNCIAS BIBLIOGRÁFICAS}

AMATO NETO, João. Redes entre organizações: domínio do conhecimento e eficácia operacional. São Paulo: Atlas, 2005.

BALLOU, Ronald H. Logística empresarial: transportes, administração de materiais. São Paulo: Atlas, 1998.

BEGNIS, Heron S. M.; PEDROZO, Eugênio A.; ESTIVALETE, Vânia F. B. Cooperação enquanto estratégia segundo diferentes perspectivas teóricas. In: ENCONTRO DA ASSOCIAÇÃO NACIONAL DE PROGRAMAS DE PÓS-GRADUAÇÃO - ANPAD, 29., 2005, Brasília. Anais... Brasília: ANPAD, 2005.
CABRAL, Augusto C. de Aquino. Novos arranjos cooperativos: alianças estratégicas e transferência de tecnologia no mercado global. In: RODRIGUES, Suzana Braga (Org.). Competitividade, alianças estratégicas e gerência internacional. São Paulo: Atlas, 1999.

CASAROTTO FILHO, Nelson; PIRES, Luis H. Redes de pequenas e médias empresas e desenvolvimento local: estratégias para a conquista da competitividade global com base na experiência italiana. São Paulo: Atlas, 2001.

CHUNG, S.; SINGH, H.; LEE, K. Complementary, status similarity and social capital as drivers of alliance formation. Strategic Management Journal, v.21, n.1, p. 1-22, 2000. 
DOLLINGER, M. J.; GOLDEN, P. A.; SAXTON, T. The effect of reputation on the decision to joint venture. Strategic Management Journal, v.18, n.2, p. 127-140, 1997.

DOZ, Y. L. The evolution of cooperation in strategic alliances: initial conditions or learning processes. Strategic Management Journal, v.17, p.55-84, 1996.

FERRELL, O. C.; HARTILINE, Michael D. Estratégia de marketing. Trad. Mauro de Campo Silva. São Paulo: Pioneira Thomson Learning, 2005.

GULATI, R. Network location and learning: the influence of network resources and firm capabilities on alliance formation. Strategic Management Journal, v.20, n.5, p.397-420, 1999.

GULATI, R. Alliances and network. Strategic Management Journal, v. 19, 1998.

KALE, P.; SINGH, H.; PERLMUTTER, H. Learning and protection of proprietary assets in strategic alliances: building relational capital. Strategic Management Journal, v.21, n.3, p.217-237, 2000.

KOTLER, Philip. Administração de marketing: a edição do novo milênio. Trad. Bazán Tecnologia e Lingüística. São Paulo: Pearson Prentice Hall, 2000.

KWASNICKA, Eunice L. Em direção a uma teoria sobre redes de negócios. In: BOAVENTURA, João Maurício Gama (Org.). Rede de negócios: tópicos em estratégia. São Paulo: Saint Paul, 2006.

MADUREIRA, Daniele. Atacado reage à venda direta da indústria ao "varejinho". Jornal Valor Econômico, São Paulo, 06 de agosto de 2007.

McDONALD, Malcom. Planos de marketing: planejamento e gestão estratégica: como criar e implementar. Trad. Arlete Simille. Rio de Janeiro: Elsevier, 2004.

NOVAES, Antonio Galvão. Logística e gerenciamento da cadeia de distribuição. 2. ed. Rio de Janeiro: Campus, 2004.
OLIVARES, J.E.L. Negociação para configurar o desenho da estrutura organizacional em rede. Caderno de Pesquisas em Administração, São Paulo, v. 9, n. 3, jul./set. 2002.

OLIVEIRA, Silvio Luiz de. Tratado de metodologia científica. São Paulo: Pioneira, 1997.

PICATTO, Gessuir; ALCÂNTARA, Rosane L. C. Uma análise das estratégias, obstáculos e benefícios do relacionamento entre redes varejistas e fornecedores de mercearia básica. In: ENCONTRO DA ASSOCIAÇÃO NACIONAL DE PROGRAMAS DE PÓSGRADUAÇÃO - ANPAD, 30., Salvador, 2006. Anais... Salvador: ANPAD, 2006.

SAKAKIBARA, M. Heterogeneity of firm capabilities and cooperative research and development: an empirical examination of movies. Strategic Management Journal, v.18, supplement, p. 143164, 1997.

SHAPIRO, S.S.;WILK, M.B. Analysis of variance test for normality (complete samples), Biometrika, 52, 591-611, 1965.

TSAI, W. Social capital: strategic relatedness and the formation of intraorganizational linkages. Strategic Management Journal, v.21, n.9, p. 925-939, 2000.

WILDER, Ariel. Mudanças no setor supermercadista e a formação de associações de pequenos supermercados. Dissertação (Mestrado em )-Escola Superior de Agricultura Luiz de Queiroz-USP, Piracicaba, 2003.

WLAKER, G. Commom statistical methods for clinical research with SAS ${ }^{8}$ Examples, Cary, NC: SAS Institute Inc., 1997. 315 p. 